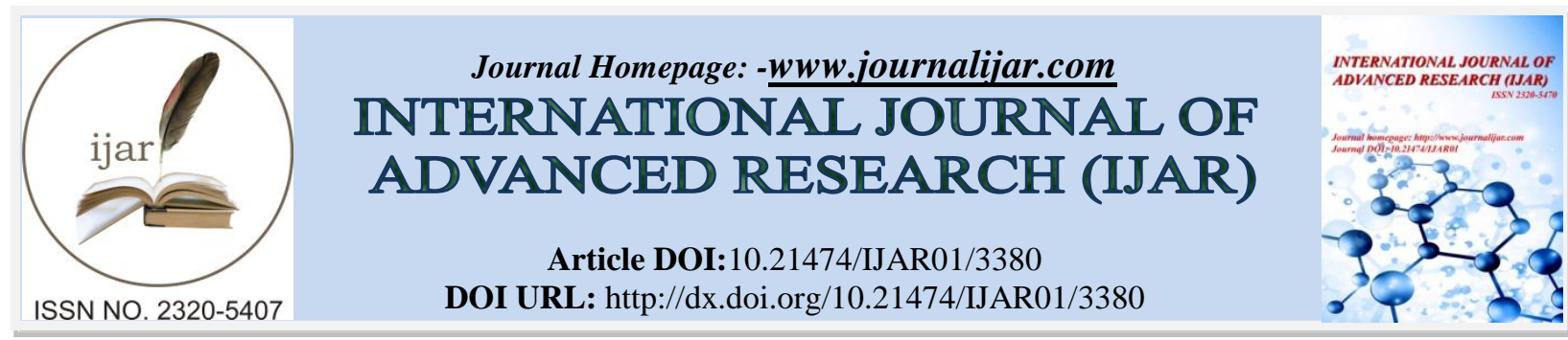

RESEARCH ARTICLE

\title{
WATER POLLUTION SITUATION AND APPLIED WASTEWATER TREATMENT STRATEGIESINBANGLADESH.
}

\begin{abstract}
"Prantor Kumar Mondal, Ying Liu, Sukhodolska Kateryna, Lirong Zeng and Hanhao.
Unep- Tongji Institute of Environment for Sustainable Development, College of Environment Science and Engineering. 20092, china.
\end{abstract}

\section{Manuscript Info}

Manuscript History

Received: 20 December 2016

Final Accepted: 14 January 2017

Published: February 2017

Key words:-

Water pollution, Wastewater, Salinity, Arsenic Contamination, and Treatment.

\begin{abstract}
Bangladesh, a developing country, located in South Asia along with large population size but with limited land. Due to rapid industrialization and urbanization, scarcity of clean water is rising up day-to-day. Contrary, contamination or pollution of water is still increasing for which many factors are playing roles. The prime source of drinking water in Bangladesh is groundwater and the wide causes for the water pollution is arsenic contamination. Then other major sources of water pollution included industrial wastewater, municipal wastewater, pesticides and chemicals usage in agriculture, road construction, oil spills, salinity intrusion, heavy metals, sedimentation deposit during the flood, and illegal disposal of suspended matters into water bodies. Currently, water pollution is a principal environmental issue in Bangladesh. With-a-view to solving this paramount problem, a lot of water treatment technologies have already been introduced in Bangladesh paradigm - physical, chemical, and biological process (shafi filter, tin kolsi method, oxidation, coagulation, precipitation, adsorption, reverse osmosis, solar desalinization, and new technology for oil removal. But in a case of industrial effluent and municipal wastewater treatment is still limited within primary treatment process. Salinity intrusion is a big problem in the whole southern part of the country but it still unresolved. Further, agricultural pesticide runoff is causing depletion of fishes but there is no step for controlling it. For removing sedimentation deposit in a river, a degrading program has already commenced but not sufficient. But still, there is not found any resource recovery process from wastewater in Bangladesh.
\end{abstract}

Copy Right, IJAR, 2017, All rights reserved.

\section{Introduction: -}

Bangladesh is a densely-populated country and being developing country, rapid and haphazard urbanization and industrialization is frequently expanding, which is responsible for significant environmental damage suchlike water pollution (Mahmud, 2003). Consequently, the water pollution in Bangladesh has become the worst problem comparing with the other pollutions based on historical data and this situation is triggering by the result of human induced activities among the poor nations of the world. A British study shows that, about 80 million people from Bangladesh (South Asia) were exposed to a high level of toxicity from the water contaminated with arsenic. Besides, an international team of researchers has detected water intake from arsenic contaminated wells and the impact of 
12,000 people in the last decade. Further, it was identified that the death of five people was directly linked to the elevated levels of arsenic in the bodies of the victims of the Bangladesh water. The problem is known for some years now and, hence local residents were advised to dig deeper wells to avoid the potentially contaminated surface water consumption (Smith et al., 2000; Mukherjee, 1999). Dhaka is the capital and the densely-populated city in Bangladesh while the biggest problem of the city is the arsenic in the water. Unfortunately, there is a plenty of dust and soil; hence the main pollution of Bangladesh is on the water. Some studies indicate that 20 years are needed for the morbid effects of arsenic poisoning to disappear. About 59 districts out of 64 are affected by arsenic contamination. Arsenic contamination level varies from 0-20,000 ppm while WHO permit level in drinking water is 10 ppm but 50 ppm in Bangladesh standard while some experts have recommended 20 ppm (Safiuddin\& Karim, 2001).

Rivers and canals in Bangladesh are becoming increasingly polluted from industrial wastewater dumping by factories, especially textile industry. Leather tanneries are also a significant source of toxic pollutants to the air and water. The important river of Dhaka city is mainly polluted due to tanneries effluent discharges. The water pollution threatens food production as well as raising both environmental and human health hazards. According to Human Rights Watch report, toxic from tanneries are seriously affecting workers like skin diseases, and respiratory illnesses caused by exposure to tanning chemicals, and limb amputations caused by accidents in dangerous tannery machinery (Miti et al., 2009). Runoff agricultural pesticides mixed water; oil spills from tankers, household wastewater discharge, and thermal water pollution from hydroelectric project are also contributing river water pollution in Bangladesh major or minor scale.

Bangladesh is a deltaic country with total area of $147,570 \mathrm{~km} 2$ where the major part consists of alluvial sediments deposited by the rivers of Ganges, Brahmaputra, Tista, Jamuna, Meghna and their tributaries. The coastal region covers about $20 \%$ of the country but in case of the cultivable lands cover more than $30 \%$. About $53 \%$ of the coastal areas are affected by salinity. Agricultural land use in these areas is very poor for salinity intrusion, which is much lower than country's average cropping intensity. The factors which contribute significantly to the development of saline soil area, tidal flooding during wet season (direct inundation), and upward movement of saline ground water during dry season. The severity of salinity problem in Bangladesh increases with the dehydration of the soil. The dominant crop grown in the saline areas is local transplanted Aman rice crop with low yields (Haque, 2006).

Pesticide use in Bangladesh is often excessive and unregulated. Despite of their worldwide ban, Persistent Organic Pollutants (POPs) and other harmful organ-chlorine pesticides are widely being used yet. The presence of POPs such as DDT in agricultural wastewater which is carried into rivers flows or nearby water bodies during rainfall causes serious water pollution. This is responsible for dying of fishes and extinction of abundance fishes from rural water bodies (Hasan et al., 2012). Consequently, the abundance fishes in water bodies of Bangladesh have already declined remarkably. A study shows pesticide sprayed in farm lands is higher dust than non-spraying. The distributions of the pesticides throughout the various rooms sampled suggest that the strictly agricultural herbicides are potentially being brought into the home on the farmer's shoes and clothing. These herbicides are not applied in or around the home but they appear to be getting into the home para-occupationally. For agricultural pesticides, takehome exposure may be an important source of home contamination (Curwin et al., 2005).

Storm water and flood water runoff carry silts and waste material into river or channel flows and thus pollute water bodies as well as fill up. This water also carries construction debris and oils from road or park lots. Moreover, deforestation, soil erosions and land use change are resulting into sedimentation deposit in water flows and finally, these water bodies are becoming dry up depleting fish resources. Therefore, pollution in Bangladesh has brought enormous problems throughout the country suchlike drinking water source destroy, irrigation water supply problems, household, and industrial water supply troubles. Defective implementation of laws and lack of awareness among mass people is retarding water pollution control efforts.

\section{Investigation Of Water Pollution Situation In Bangladesh: -}

Day-to-day water pollution situation in Bangladesh is becoming worsened. The factors which are responsible for water pollution and increasing severity are diversifying frequently as well as new sources are adding everyday due to rapid population growth, economic growth, improvement of living standard, and more chemicals, pesticides, and heavy metal usages for different purposes. But they are still under control range. The major types and sources of water pollution in Bangladesh are described as follows. 


\section{Municipal Wastewater: -}

Bangladesh is an over populated country and urbanization process is continuously expanding frequently but indiscriminately. There are 11 city corporations, 119 municipalities and 310 urban centres while urban population rate is $28.4 \%$ now. Besides, about 3-4 \% people are migrating to the urban areas every year for searching of livelihood or better living standard (BBS, 2011). Hence, high rate of rural people migration to urban areas is worsening the environmental situation. Consequently, more population is producing large volume of wastewater and directly discharging into water bodies. Hence water pollution from municipal household sources is a big problem in Bangladesh now. Further, per capita polluted water discharge and per capita pollutant load in water bodies in rising up. For detecting the pollutant load in the river, river flow fluctuation derived from the tidal level fluctuation was important to be considered in regards to both water quantity and quality (Parvez et al., 2007). Enough knowledge about the nature of wastewater is essential to design and operate collection, treatment, and disposal process to manage quality of environment. As example: Municipal wastewater of Sylhet city originates from different types of sources and then falls into the Surma River through different channels without any treatment. The discharged wastewater quality of Sylhet city is medium for suspended solids, BOD and chlorides, and strong for alkalinity (Alam et al., 2006).

Similarly, in other cities like Khulna Municipal area wastewater is discharged to the nearby rivers, canals, etc. without treatment. The observed values of different parameters lie within the range to permit reuse in agriculture. The values of DO are found to be below the permissible level recommended for irrigation while some values of EC and TDS exceed the irrigation water quality standards. Chloride was the dominant anion following bicarbonate, sulfate, phosphate and nitrate whereas calcium is the dominant cation following magnesium, sodium and potassium in wastewater generated in Khulna city. This domestic effluent dominated wastewater flow through the numerous concrete and earthen drains which finally dispose of to the nearby water bodies without treatment. As the quality of wastewater is not fully satisfactory, there are valid probabilities for occurring pollution problems in river waters (Mridha, 2011). In the same way, others cities of Bangladesh paradigm Dhaka, Chittagong, Rajshahi, Barisal, Gazipur, Narayangonj, Comilla, and Rangpur discharge their daily generated municipal wastewater into nearby water bodies (especially river) without making any pre-treatment which is responsible for polluting the concerning water bodies. Thus the water pollution situation in Bangladesh is enhancing rapidly which has become a tough task to control if it is delayed.

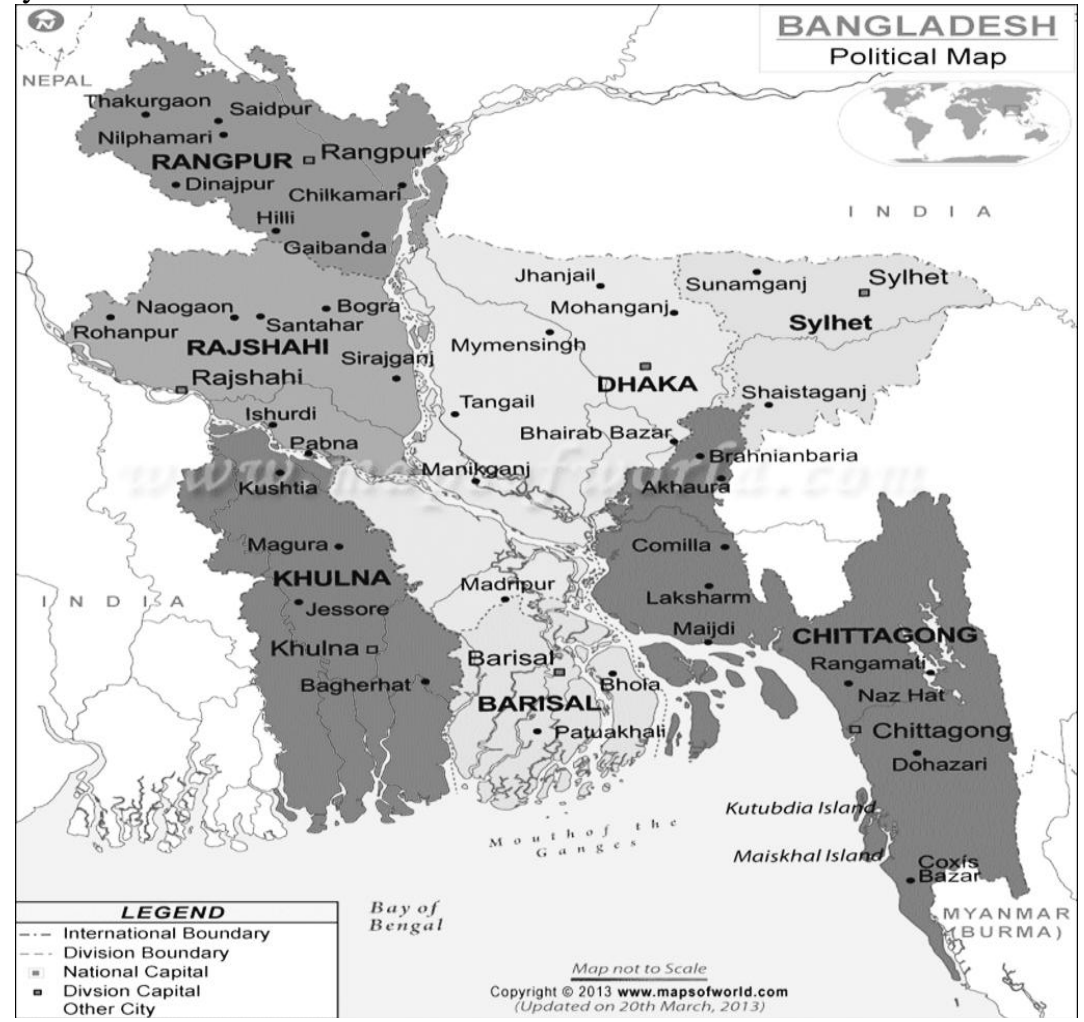

Figure 1: - Bangladesh political map indicating major cities 


\section{Industrial Wastewater: -}

There are total 30 industrial estates in Bangladesh currently according to Bangladesh Small and Cottage Industries Corporation (BSCIC). BSCIC was created through an Act of Parliament in 1957 which was later amended in 1992. Likewise, the Bangladesh Export Processing Zones Authority (BEPZA) was established to setup and operate export processing zones in Bangladesh under the Bangladesh Export Processing Zones Authority Act, 1980. According to Act the Chittagong Export Processing Zone (CEPZ) was established in 1983 and later, the Dhaka Export Processing Zone (DEPZ) created in June 1993. The rest industrial parks are dispersedly located in different parts of Bangladesh mainly in Chittagong, Dhaka, Khulna and some others placed in distinct place of the country (Yunus and Yamagata, 2012).
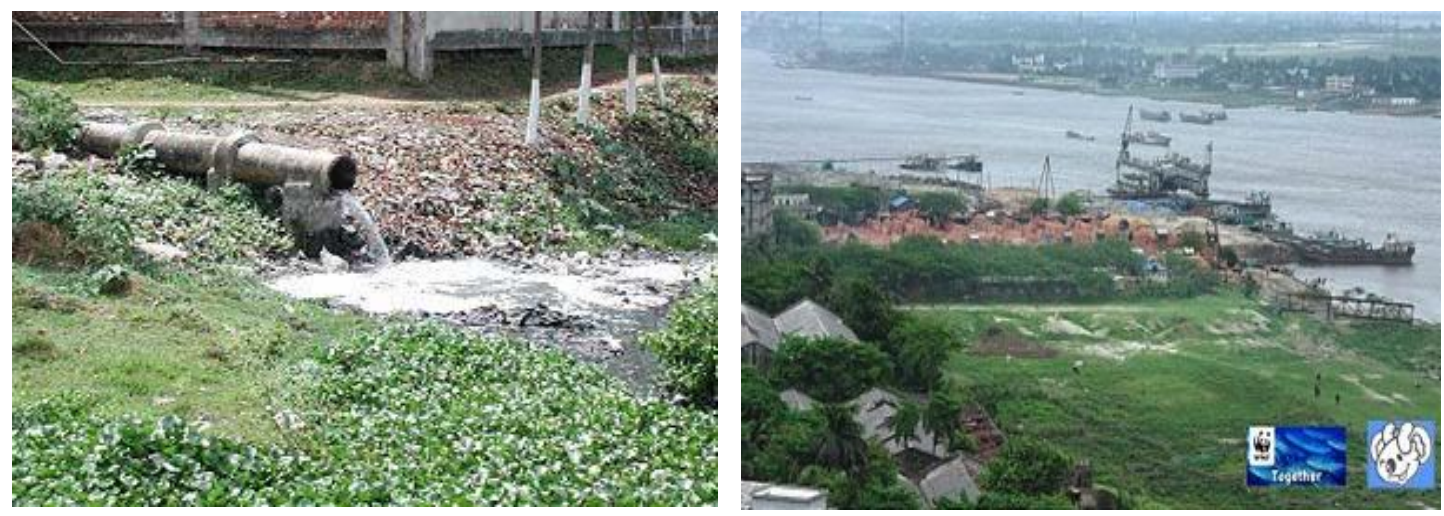

Figure 2:- Industrial effluent discharge and river water pollution in Dhaka

The most polluting industries are tanneries, textiles, chemicals, dying and pharmaceuticals factories. All the industries produce gigantic volume of effluent every day during their normal operations as by-products. This wastewater contains TDS, TSS, heavy metals, nutrients, and toxic chemicals which are responsible for destroying water quality and making unsuitable water bodies for survivable of organism as well as for other purposes of use like household, irrigation, industrial, and drinking. Almost all the factories discharge their daily generated wastewater directly into nearby water bodies without any pre-treatment. Majority number of industrial units has their own effluent treatment plants (ETP) but they don't use regularly to save cost. Only a few industries partially operate their installed ETP regularly. All the ETP use mainly biological process to remove BOD, TSS, and others. But they don't collect nutrients and heavy metals from wastewater. Therefore, their treated wastewater is also unsafe for further usage (Yardley, 2013).

\section{Groundwater Pollution: -}

The groundwater has been used for agricultural and drinking purpose since 1960's in Bangladesh. With a view to bringing change in conventional groundwater extraction system, another initiative based on pervious agencies on principal began to supply of safe drinking water for rural people by installing tube wells headed by UNICEF in 1970s. Unfortunately, this project was the cause of one of the worst environmental calamities in the delta's history. Arsenic is a naturally occurring element that exists in the earth. Besides, most of the tube wells weren't penetrated into deep rather extracts subsurface water. But there is more potentiality of arsenic availability in sub surface water source. Consequently, later for the past two decades the water from over a million tube-wells has been slowly poisoning with naturally occurring arsenic predominantly in the village areas. According to WHO, up to half the country's tube wells, estimated to number 10 million, are poisoned by arsenic contamination (2001). Hence, it is estimated that about 35 to 100 million people are at risk of drinking arsenic-contaminated and large scale groundwater extraction is the root cause of arsenic contamination in the ground water.

Purification of drinking water using various methods was practiced in ancient India and it is a shame to find the very source of potable water contaminated in the Bengal Basin. The region has constantly struggled in its attempt to administer safe and adequate water resources, making it easier for people in the Bengal Basin to access safe drinking water. By the late 1980s, surface water was the main source of drinking water in the region which was severely polluted. As a result, the population largely suffered from diarrhea and various water-borne diseases. Then Bangladesh government, UNICEF and various other aid groups suggested using groundwater as an alternative source for drinking water. This idea seemed logical because of the ample number of aquifers in the Bengal Basin and the deltaic alluvium which was easy to dig (Telfeyan, 2009). 
In 1993, studies detected the first patient suffering from arsenic-contaminated groundwater. The Bangladesh government began to face a very difficult and serious water problem. Arsenic is a known as carcinogen and highly toxic substance. It has gradually affected people in the Bengal Basin. But it is difficult realize that drinking water is affected by arsenic because it is colourless, tasteless and odourless. Now, this disaster is widespread in the Bengal Basin and about one-third of the population of the Bengal Basin suffers from various diseases suchlike warts, skin lesions, and cancers. This serious water problem can be attributed to the combination of ineffective water resource management, industrialization and the rapid increase of population. Anyhow, the arsenic-contaminated groundwater problem is mainly caused by the lack of knowledge of water resources (Mukherjee, 1999).

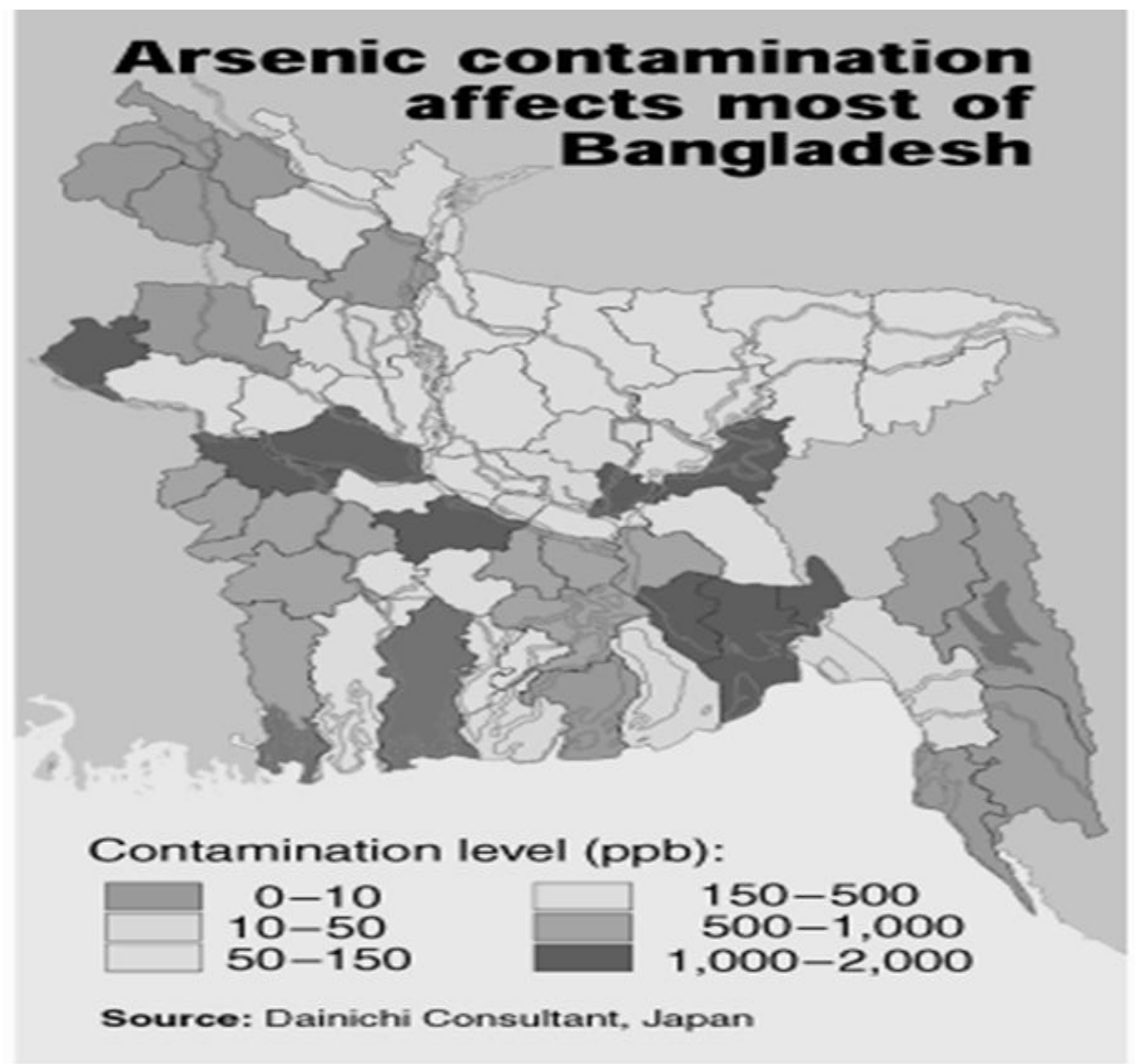

Figure 3:- Arsenic contamination showing map of Bangladesh

\section{Salinity Intrusion in Fresh Water Sources: -}

Bangladesh is a riverine country and the whole southern part of the country is covered by the Bay of Bengal. But the water of the Bay of Bengal is saline and so the southern part of the country is affected by salinity intrusion through ground water infiltration or inundation by flood water. Moreover, salinity intrusion is an impact of climate change and it has become a common phenomenon in the country's coastal belt. The intrusion of salt water into arable land is now severely affecting boro rice cultivation in the dry season. But about 2.85 million hectares of land is available in the coastal belt where only 0.83 million hectares of land is cultivable amidst 0.44 million is now salt-affected (Haque, 2006). As a result, they can't grow rice in their belonging lands due to salinity effects. Contrary, a large number of farmers are cultivating boro rice in salt-affected areas, while most of them are using hybrid rice and local rice variety which require 145 to 160 days to harvest. Farmers need to prepare seedbeds in November, followed by main land preparation and transplanting of rice seedlings in the main field in December-January. Similarly, the farmers are facing serious problem in cultivating boro rice due to increasing salinity intrusion in these areas. So, they get low yields and sometimes no yield at all (Hassan, 2009; Haque, 2006). 
For overcoming rice production problem, Bangladesh Institute of Nuclear Agriculture (BINA) in collaboration with International Rice Research Institute (IRRI) has developed salt-tolerant rice variety named Binadhan-8 which can survive up to $10 \mathrm{ds} /$ metre. The National Seed Board of Bangladesh officially released Binadhan -8 in 2010 to enable farmers to cultivate this variety a larger scale in the salt-affected areas. With this variety, it is possible to yield six tons per hectare in salt-free land. So Binadhan- 8 can be cultivated in both salt-affected and salt-free lands (BINA, 2014).

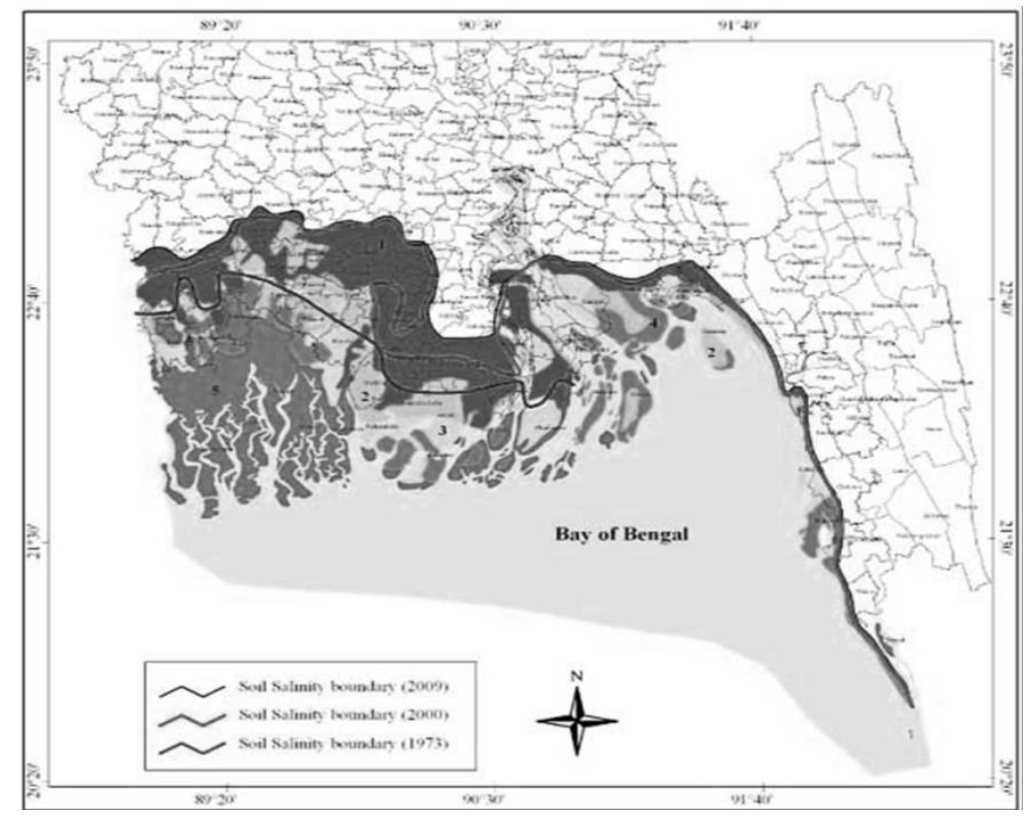

Figure 4: Salinity intrusion extent in different time in the southern part of Bangladesh map.

Anyhow, farmers in the southern region of the country got desired results from this salt-tolerant rice variety under close technical follow-up and supervision by IRRI and DAE field staff and its partner NGOs as well as private seed companies. It was found that without any salinity, farmers received around 5.5 tons of rice per hectare, which required 135-145 days to harvest. But when the variety was planted in salt-affected lands (8-12 dsm/metre), farmers received around three to four tons of rice per hectare, depending on the degree of salinity. Both farmers and farm labourers of the coastal areas are getting benefits from the cultivation of Binadhan-8, which is salt-tolerant and highyielding (Haque, 2006).

\section{Agricultural Pesticides: -}

Bangladesh is an agricultural country. Most of the part of the country is fertile but total land area is limited. Besides, rice and fish are our staple food. Moreover, our population volume is large along with high growth rate. For meeting the high demand of food, farmers are using more pesticides and chemical fertilizers for getting highest production within limited land. But these pesticides are very harmful for environment and fishes though they can destroy insects. During heavy rainfall and flood this agricultural wastewater runoff into nearby water bodies or rivers and get mixed with river water and occur water pollution. For this reason, our historical abundances of fish is declining rapidly and appearing scarcity of fishes. Pesticides and chemical fertilizers use in agricultural crops or farm is the main cause of fish reduction in Bangladesh (Kabir and Rainis, 2012). In many developed countries, this harmful and toxic pesticides use has already banned for saving environment. But in developing countries like Bangladesh, these pesticides are still widely used in agriculture and farms. 


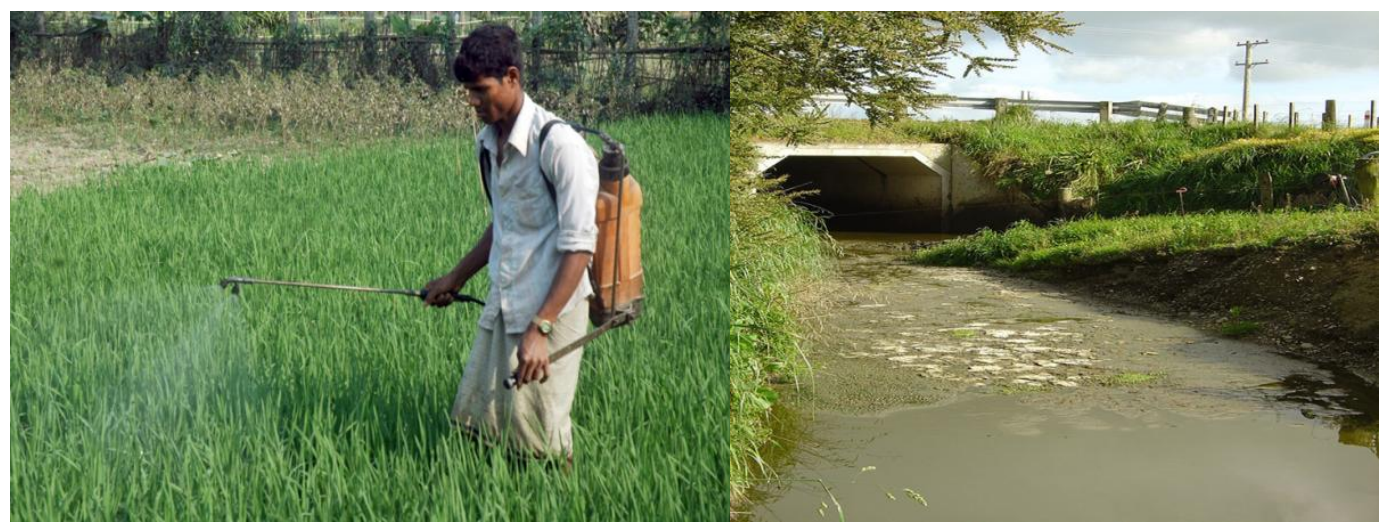

Figure 5: - Agricultural pesticides use and nearby water bodies' pollution

Oil Spills and Road Construction Materials: -

Bangladesh imports all the consuming oil from middle estate countries. Therefore, oil pollution is not a familiar and serious pollution in Bangladesh. But when some ships discharge their oily wastewater directly into the Bay of Bengal or wash up their ship then water pollution occurs. The Bay of Bengal is vast, so it is not a big problem. On the other hands, road construction and park lots oil mixed materials get mixed with rain water runoff during heavy rainfall and flood which is finally carried into Inland River or channel waters and happen water pollution. Very recently, $\left(9^{\text {th }}\right.$ December, 2014) a large-scale oil spills took place in Sela River of Sundarbans. Consequently, the fragile Sundarbans region stared at an ecological nightmare after a vessel carrying 350 tonnes of oil crashed, spilling the toxic liquid over an $80-\mathrm{sq}-\mathrm{km}$ area along the Sela River in Bangladesh and threatening a sanctuary of rare Irrawaddy and Ganges dolphins. Sundarbans, a UNESCO world heritage site, has a unique land-marine eco-system which includes the Bengal tiger. The tanker, Southern Star VII, sank after colliding with another vessel early Tuesday while trying to steer through dense fog. Now it is considered as an ecological catastrophe (Mukherjee and Chakrabarty, 2014).
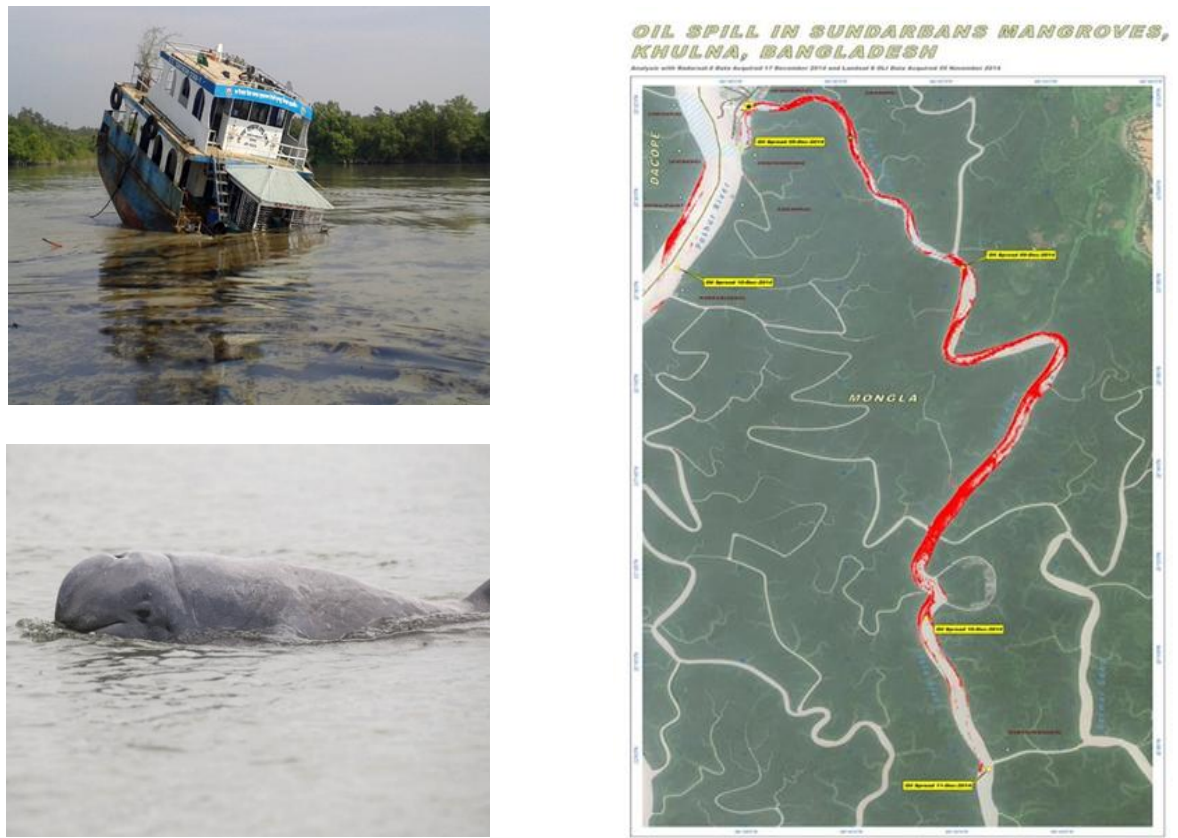

Figure 6: - Oil spills from tanker (left) and oil spread through river map (right)

\section{Thermal Water Pollution: -}

Thermal pollution is not a big factor in Bangladesh now. But it is increasing gradually due to rapid industrial growth. Majority of the industries in Bangladesh directly discharge their used water into nearby water bodies making hot. This hot water reduces oxygen availability of the water and make unsuitable for fish survival. Besides, in Chittagong there is one hydro-electric project which use river water and discharge the used hot water into Kaptai 
Lake. Consequently, it is decreasing oxygen availability from the lake which is resulting into fish production or survival problem.

\section{Natural Disasters (Flood and Storm): -}

Bangladesh is a disaster-prone zone and many natural disasters visit this country every year suchlike flood, cyclone and storm. These disasters sweep away waste, silt and clay from land during disasters and deposit in river, channel, lake or wetland water and cause water pollution. It is also responsible for occurring eutrophication process in lake or lagoon because this water runoff carries nutrients along with wastes.

\section{Some Applied Strategies for Wastewater Treatment In Bangladesh: A Few Case Studies:}

Currently, Bangladesh is giving priority on arsenic removal from ground water, municipal sewage treatment, industrial effluent treatment, and salinity removal from coastal inland water sources and they are major concerning issues too. All the major water pollution control process and technology are described below -

\section{Municipal Wastewater Treatment: -}

Municipal sewage treatment is one of the biggest problems in Bangladesh but still neither central government nor local government has taken proper steps to resolve this trouble rather they are planning to do something for treatment of sewage. Anyway, Dhaka City Corporation had established one sewage treatment plant namely Pagla Sewage Treatment Plant in 2003 which can treat only 10\% comparing to the total daily sewage generation. The current area and population of Dhaka city is $348.57 \mathrm{sq}$. km. and about 15 million. Consequently, this large population generate huge volume of sewage which demands more sewage treatment plants. Hence, one study suggests that Dhaka city need five new sewage treatment plants immediately to increase efficiency. In case of sewage treatment, they use conventional treatment process and limited within primary treatment (figure 7). But in case of other cities there is no sewage treatment plant yet. So, major fraction of sewage is remained untreated and causes water pollution (Amin, 1998; Arafin, 2011).
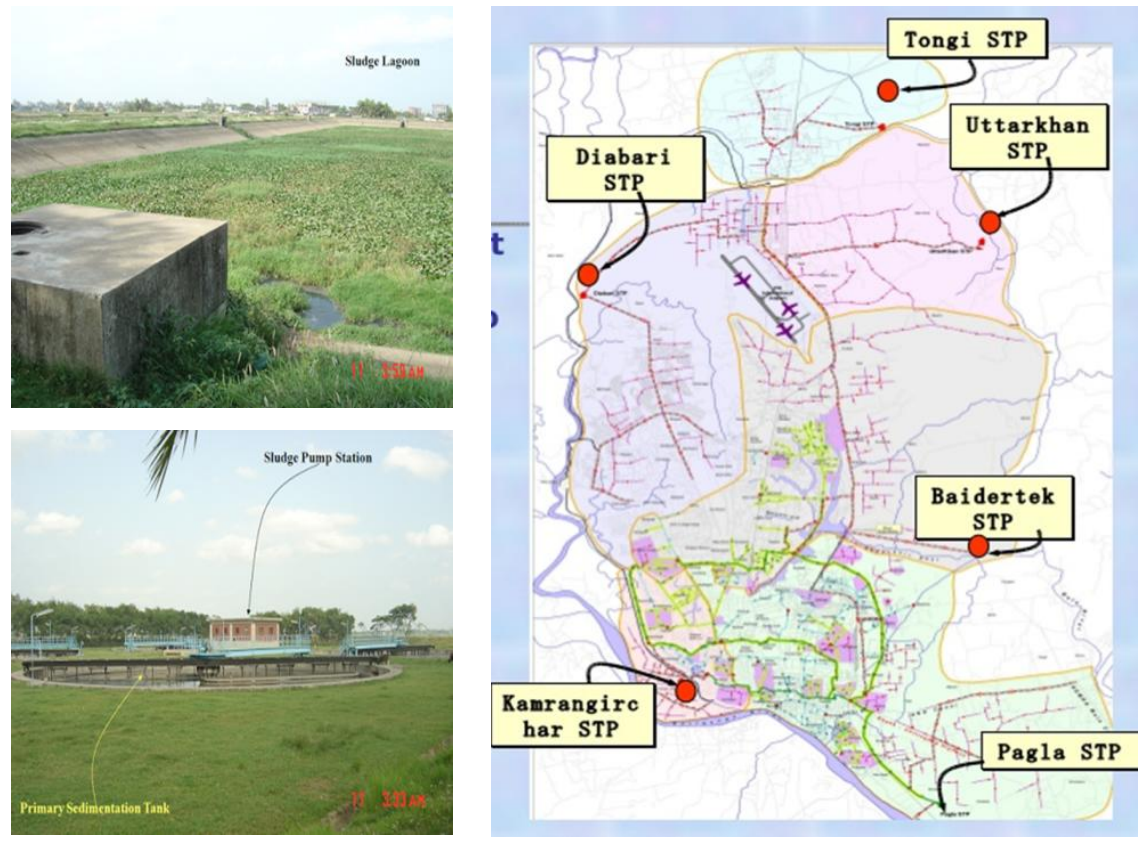

Figure 7: - Pagla Sewage Treatment Plant, Dhaka (left) and proposed map for new plants.

While for sewage and drinking treatment, there are six plants in Dhaka city and they can supply only about 35\% and the rest comes from ground water. Then in other large cities suchlike Chittagong, Khulna, Rajshahi, Sylhet, Barisal, and Narayonganj they have only drinking water treatment plant but no sewage treatment plants still. 


\section{Industrial Wastewater (effluent) Treatment: -}

In Bangladesh industrial growth is rapidly occurring but in haphazard and unplanned way.Most of the small-scale industry has no effluent treatment plants. Contrary, medium and large scale industries have their own effluent treatment plants but don't operate regularly with a view to saving cost. But the large-scale industries that operate their sewage treatment regularly are not sufficient because they do partially not fully. Most of them use physical, chemical and biological process mixing up as well as conventional technology. But they give priority mainly on biological process rather than chemical ones. Very few small industrial parks in Dhaka has their common effluent treatment plants while large scale common effluent treatment plants are only in Chittagong and Dhaka located at Chittagong Export Processing Zone and Dhaka Export Processing Zone. There is given one process flow chart of effluent treatment in Bangladesh (figure 8) (Alam\&Guha, 2012).

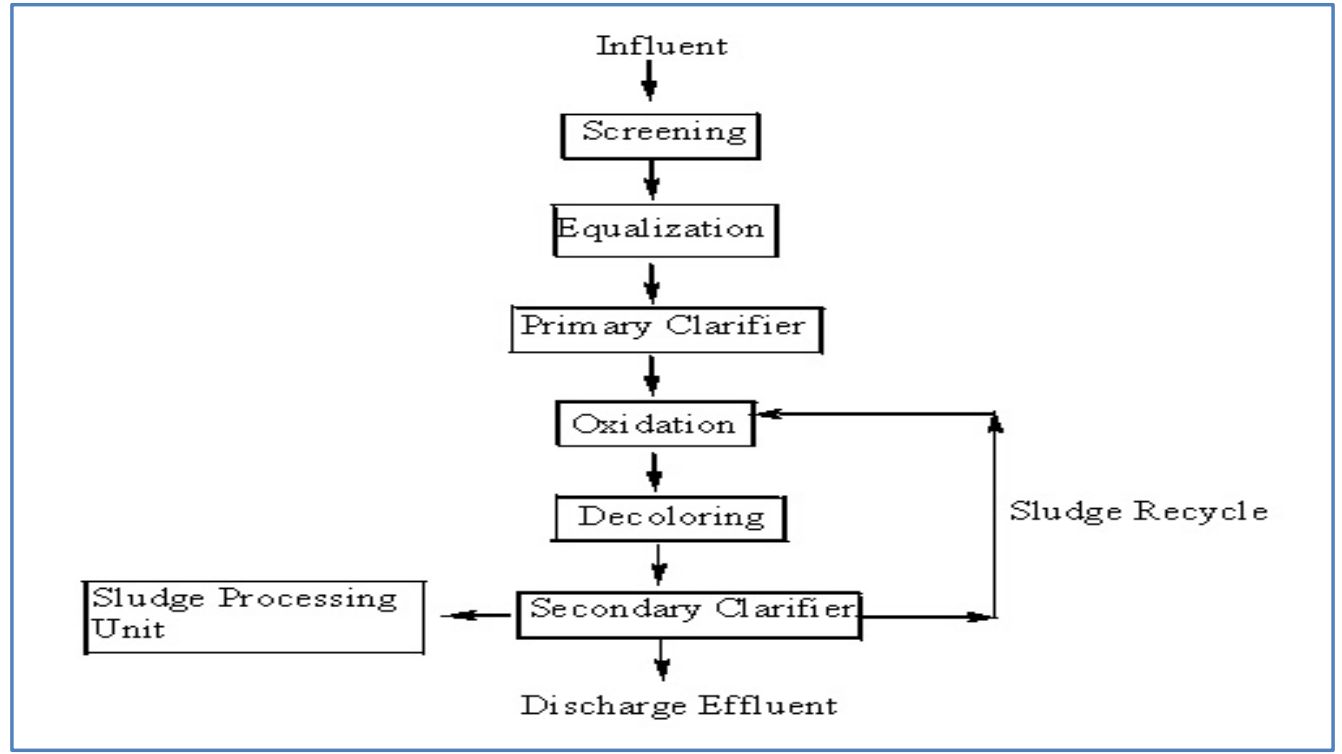

Figure 8: - Industrial effluent treatment process flow chart.

\section{Arsenic and Iron Removal from Ground Water: -}

The presence of elevated levels of arsenic in groundwater has become a major concern around the world, especially in South Asia. Up to date, there is no effective treatment for curing health impacts due to the intake of high levels of arsenic. A wide range of technologies has been developed for the removal of high concentrations of arsenic from drinking water. The most common arsenic removal technologies use oxidation, coagulation, precipitation adsorption, ion-exchange and membrane techniques while local technologies are Shafi filter and Tin-Kolsi Method. All the arsenic treatment technologies ultimately concentrate arsenic in the sorption media, the residual sludge or in a liquid media. To avoid indiscriminate disposal and environmental pollution, these wastes need to be treated or disposed of properly. In the areas where the drinking water contains unsafe levels of arsenic, the immediate concern is finding a safe source of drinking water. There are two main options: Finding a new safe source or removing arsenic from the contaminated source. If an arsenic safe water source cannot be established, the short-term goal is to reduce arsenic levels. There are several methods available for removal of arsenic from water. Both local and import technologies can remove arsenic 3-20 ppm while the highest level of arsenic contamination in Bangladesh is about 20,000 ppm. Besides, the government has taken one step to keep away people from collecting drinking water from arsenic contaminated sources by painting red colour in affected one and green colour in arsenic free one. Thus, people are being aware about arsenic. Now people are using many methods for arsenic removal at household level and three from them are shown in (figure 9) (Ahmed, 2001). 

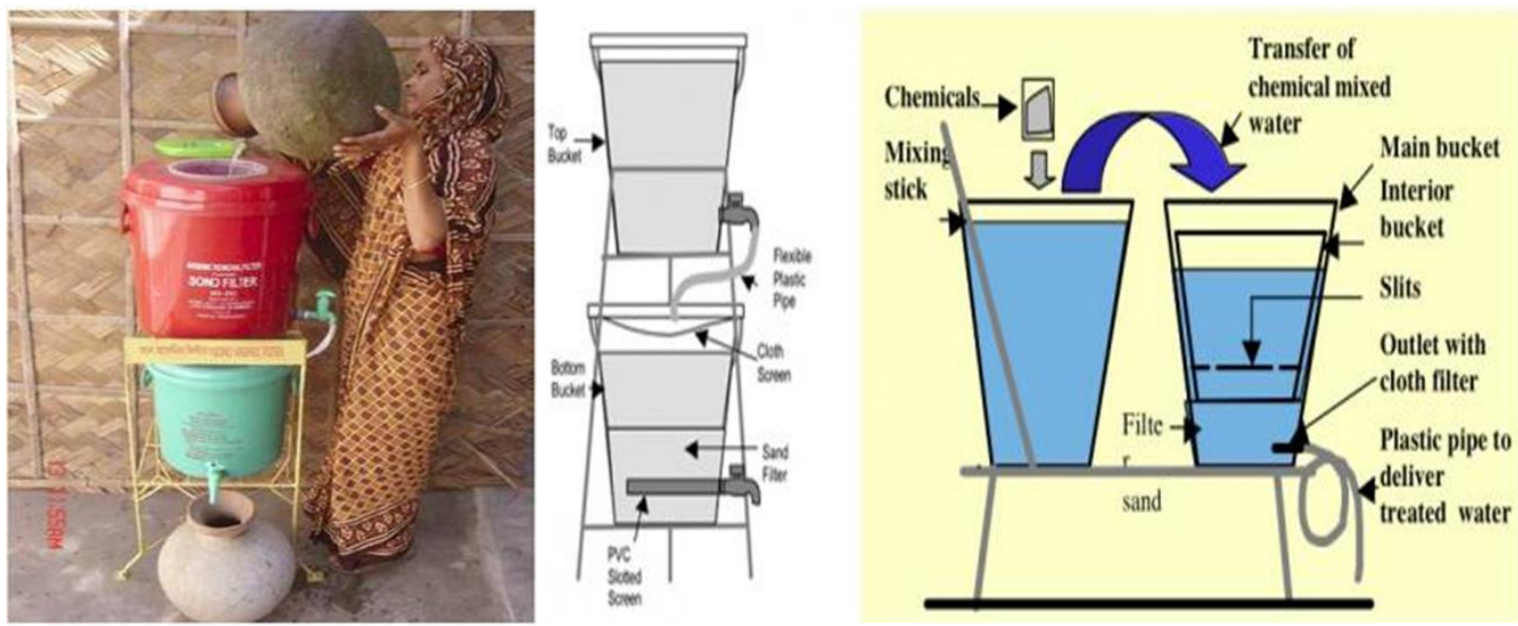

Figure 9: Sono filter (left) and bucket treatment Unit (middle), and Stevens Institute Technology (right) householdlevel filters for arsenic removal from drinking water.

\section{Desalinization of Drinking Water: -}

Salinity intrusion into drinking water source and agricultural land is a big problem in the southern part of Bangladesh. Hence, they suffer from different water-borne diseases and can't grow crops. For resolving this problem many technologies have been imported from other countries but costly and not sufficient according to social and community demand (Sobuz et al., 2010). Meanwhile, some local technologies are also developed for removing salt from water suchlike -

* Reverse Osmosis (RO) Method,

* Solar Desalinisation,

* Multi-Stage-Flash (MSF),

* Multieffect-Distillation (ME) with Thermal Vapour Compression (ME-TVC), and

* Thermal Solar Desalinization.

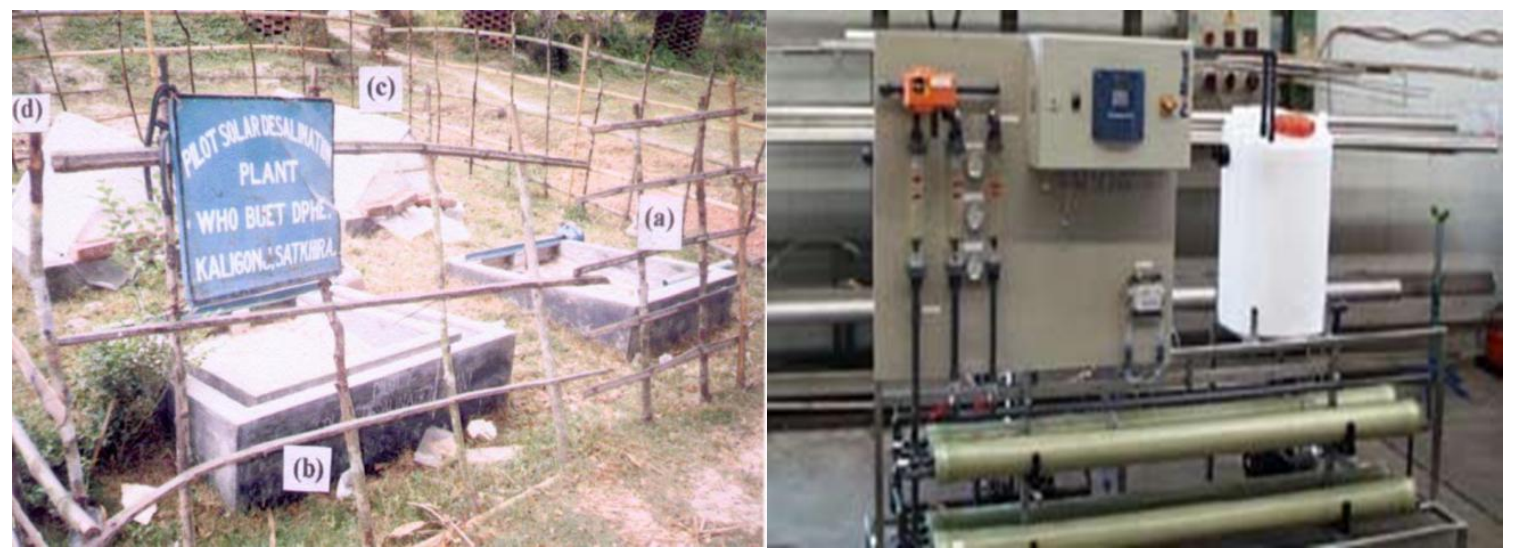

Figure 10: - Solar desalination plants at Kaligoanj, Khulna (left) and RO Plant (right)

Anyhow, the situation is gradually changing and many national and international NGOs are working together with Bangladesh government to resolve this problem. But still the problem is unresolved though many technologies have been imported and developed due to lack of sufficient fund and awareness among mass people. Contrary, some saline tolerant varieties of crops have also been invented by Bangladesh Rice Research Institute.

Agricultural and Oil Contaminated Water Treatment: -

Agricultural pesticides and chemical fertilizers mixed wastewater from agricultural field and farms are runoff into surrounding water bodies and pollute water. The whole country is suffering from this problem but no initiative has been adopted still to remove it though it the root cause of fish reduction from our natural water bodies. Once, natural sources of fish were abundance with varieties of fishes but now it is just like a dream. 
Then oil pollution is also getting remarkable due to uncontrolled trend of it. Bangladesh is much undeveloped in case of oil pollution treatment of water. Oil is used as fuel both in land and water transport along with some oil mixed materials in construction works but they are not conscious about its misuse and getting polluted water bodies. Chemical spray, neutralization process, and hand collection are the available technologies for oil removal from water but last year a new technology was developed based on local ones.

\section{Concluding Remarks: -}

Comparing with the population growth, the industrial development and urbanization process is also expanding. Consequently, water scarcity is intensifying as well as water pollution is triggering day-to-day. Arsenic contamination, salinity intrusion, industrial effluent discharge, and municipal wastewater discharge are the major water pollution is Bangladesh now. Large scale industrial wastewater treatment plants are in Chittagong and Dhaka. Then in case of municipal wastewater treatment, there is only one Sewage Treatment Plant in Dhaka. For desalinization sea water, in the Khulna there are a few small or medium scale treatment plants but not sufficient. Almost the whole country is affected by arsenic contamination as well as Dhaka and Chittagong is more polluted cities in Bangladesh. The rest cities and places are not so seriously polluted. Therefore, that still it is possible to protect the whole country being polluted because the extent of present water pollution situation is under control. But appropriate policy, plan, and public awareness are required to resolve the problem first.

\section{References:-}

1. Ahmed, M.F., 2001. An Overview of Arsenic Removal Technologies in Bangladesh and India.

2. Alam, M.I., and Guha, A.K., 2012. Designing, Construction, Validation of Laboratory Type Textile Effluent Treatment Plant for Sustainable Green Environment. Bangladesh Textile Today, a Comprehensive Publication for the Textile and Apparel Industry.

3. Alam, R., Musthaq, A., Chowdhury, M.A.I., 2006. Municipal Wastewater Characteristics of Sylhet City, Bangladesh. Electronic Green Journal, 1(23) Amin, A.F.S.M., Shamsuddin, S.A.J., Alam, M.M., 1998. Optimization of Sewage Treatment Process at Pagla. $24^{\text {th }}$ WEDC Conference on Sanitation and Water for all, Islamabad, Pakistan.

4. Arafin, S., 2011. WASA Plans Tk . 4500 cr. for 5 Sewage Treatment Plants at Dhaka. PriyoNews, Published on June 27, 2011.

5. Bangladesh Institute of Nuclear Agriculture (BINA), 2014. New Salt Tolerant Rice Variety:Hope for the Coastal Farmers. Available http://www.google.com/url?q=http://www.bina.gov.bd/index.php\%3Foption\%3Dcom_content\%26view\%3Dart icle\%26id\%3D102:salt-tolerant-rice-variety\%26catid\%3D34:research-update\&sa=U

6. Bangladesh Bureau of Statistics (BBS), 2011. Population and Housing Census - 2011. Socio-economic and Demographic Report, National Series, Volume - 4. Statistics and Informatics Division (SID), Ministry of Planning, Bangladesh.

7. Curwin, B.D., Hein, M.J., Sanderson, W.T., Nishioka, M.G., Reynolds, S.J., Ward, E.M., Alavanja, M.C., 2005. Pesticide Contamination inside Farm and Nonfarm Homes. J Occup Environ Hyg., 2(7):357-67.

8. Hassan, A.W.R., 2009. Agricultural Adaptation to Climate Change at local level in Bangladesh. Manager"Livelihood Adaptation to Climate Change" ProjectDepartment of Agricultural Extension (DAE) Ministry Of Agriculture Dhaka, Bangladesh Hasan, S., Rabbani, K.A., Hossain, M.A., Rahman, M.L. 2012. Persistent Organic Pollutants and Pesticide Residues in Seasonal Waters of Rural Bangladesh. International Journal of Environment 04/2012; 2(1):41-47Haque, S.A. 2006. Salinity Problems and Crop Production in Coastal Regions of Bangladesh. Pak. J. Bot., 38(5): 1359-1365.

9. Kabir, M.H., Rainis, R., 2012. Farmers' Perception on the Adverse Effects of Pesticides on Environment: The Case of Bangladesh. International Journal of Sustainable Agriculture 4 (2): 25-32, 2012 ISSN 2079-2107

10. Miti, S.S., Hossain, S.M.N., Rahman, L.M., 2009. A Study on the Industrial River Pollution in DMDP Area and Planning Approaches. The Jahangirnagar Review, Part 2: Social Sicence, Vol., 33, 2009 Mahmud, W., 2003. Bangladesh: Development Outcomes and Challenges in the Context of Globalization. The Conference on the Future of Globalization: Explorations in Light of Recent Turbulence co-sponsored by the Yale Center for the Study of Globalization and the World Bank, October 10-11, 2003, Yale University.

11. Mukherjee, A. B., 1999. Causes and Effects of Arsenic Contamination in Drinking Water in Bangladesh: A Critical ReviewMukherjee, K. and Chakrabarty, R., 2014. 350-tonne oil spill by Bangladeshi ship threatens

12. Sunderbans. The Times of India, published on December 12, 2014Parvez, M.I., Hussain, M. D., Ali, M. R., 2007. Present Status of Wastewater Utilization in Bangladesh: A Case Study in MymensinghPeriurban Area. AGRICULTURA TROPICA ET SUBTROPICA VOL. 40 (2) 2007Safiuddin, M., Karim, M. M., 2001. 
Groundwater Arsenic Contamination in Bangladesh: causes, effects and remediation. Proceedings of the 1st IEB international conference and 7th annual paper meet; 2001 November 2-3; Chittagong, Bangladesh: Institution of Engineers, Bangladesh.

13. Smith, A. H., Lingas, E. O., Rahman, M., 2000. Contamination of drinking-water by arsenicin Bangladesh: a public health emergency. Bulletin of the World Health Organization, 2000, 78 (9) Sobuz, H.R., Ahmed, E., Hasan, N.M.S., Islam, M.S., 2010. Study on Removal of Brick Clay Salinity in the Manufacture of Conventional Structural Bricks. International journal of civil and structural engineering volume 1, no 3, Telfeyan, K., 2009. Groundwater Contamination in Bangladesh: Causes, Effects, and Remediations. Poverty and Human Capability Capstone.

14. Yardley, J., 2013. Bangladesh Pollution, Told in Colors and Smells. The New York Times, Published on July 14, 2013.

15. Yunus, M., Yamagata, T., 2012. The Garment Industry in Bangladesh. Fukunishi ed., Dynamics of the Garment Industry in Low-income Countries: Experience of Aisa and Africa (Interim Report). ChousakenkyuHoukokusho, IDE-JETRO, 2012. 